\title{
The complex links between governance and biodiversity
}

\author{
C. Barrett ${ }^{1}$, C. Gibson ${ }^{2}$, B. Hoffman ${ }^{2}$, M. McCubbins ${ }^{2}$ \\ department of Applied Economics and Management, Cornell University, Ithaca NY, \\ USA \\ ${ }^{2}$ Department of Political Science, University of California at San Diego, La Jolla, \\ California, USA
}

Keywords: conservation policy, governance, corruption, elephants, forests, politicș, environmental policy, biodiversity

\begin{abstract}
We argue that two problems weaken the claims of those who link corruption and the exploitation of natural resources. The first is conceptual. Studies that use national level indicators of corruption fail to note that corruption comes in many fofms, at multiple levels, that may affect resource use quite differently: negatively, positively or not at all. Without a clear causal model of the mechanism by which corruption affects resources, one should treat with caution any estimated relationship between corruption and the state of natural resources. The second problem is methodological. Simple, atheoretical models linking corruption measures and natural resource use typically 4o not account for other important control variables pivotal to the relationship between huijaans and natural resources. By way of illustration of these two general concerns, we demonstrate that the findings of a recent, well-known study that posits a link between corruption and decreases in forests and elephants are not robust to simple conceptuaf and methodological refinements.
\end{abstract}

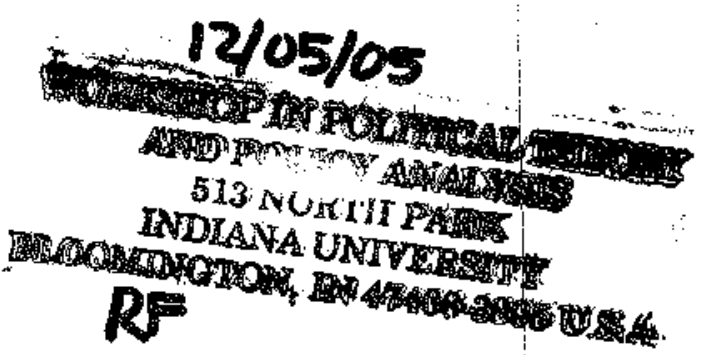




\section{Acknowledgements}

We thank R. Barnes, T. Katzner, S. Lahn, D. Squires, and three anonymous reviewers for helpful comments on this study and R. Smith for helpful clarifications regarding the data and methods he and his colleagues used. 


\section{The complex links between governance and biodiversity}

\section{Introduction}

Government corruption gained popularity as an explanation for environmental degradation with the drastic decline of forests and certain species of wildlife in the 1970s and 1980s (Myers 1979; Hecht \& Cockburn 1989; Gibson 1999; Ross 2001). Indeed, it seems only commonsensical that politicians and officials with short time horizons and few legal checks on their power might augment their wealth (and the wealth of their supporters) by supporting the over-harvesting of natural resources such as forests and wild animals. Corrupt politicians and bureaucrats have certainly played a key role in environmental degradation, as numerous case studies suggest (Myers 1979, Hecht and Cockburn 1989, Ross 1996, Ascher 1999; see Ross 2001 for extensive references).

Given the case study evidence, more recent studies have understandably sought to make more generalizable claims about the connection between corruption and environmental outcomes by testing hypotheses with cross national data. Exploiting relatively new data sets that offer measures related to national-level governance quality, some analysts have found significant relationships between proxies for politics, corruption, and resource outcomes (Deacon 1994, 1999; Bohn and Deacon 2000). Perhaps the best known of the recent studies is R.Smith et al.'s (2003) analysis in Nature, which finds strong relationships between corruption and the decline of elephant, rhinoceros, and forests. Their results add empirical plausibility to arguments directly linking corruption and biodiversity loss. Others, such as Katzner (2005), use similar methods to generate opposite results. 
This paper offers a caution about this new direction in the literature. We argue that conventional wisdom about the connection between natural resources and corruption may be quite misleading and that these links remain largely untested in any rigorous way. Given the state of theory and tests, inferences as to the complex relationship between governance and biodiversity should be made with great caution.

The structure of the paper is as follows. First, we explore the hypothesized relationships between corruption and biodiversity. Corruption and environmental outcomes are commonly both the result of sets of political and economic institutions at different levels that are weak or missing (Barrett et al. 2001). Corruption operates on different levels, is of different types, and will have different effects given different kinds of resources. Consequently, corruption and natural resources might be related, but not in the causal ways commonly posited in simple models. Indeed, the causal relation, if any exists, could plausibly involve corruption reducing, rather than accelerating, natural resource degradation.

This discussion naturally leads to the second substantive portion of the paper, which underscores the fragility of statistical results purporting to provide hard evidence on the links between corruption and biodiversity. Methodological weaknesses in such analyses arise due to the standard problem in observational data that there exist no natural experiment with proper controls already in place. Such concerns, while familiar to social scientists (see, for example, the extensive literature on economic growth based on cross- 
country regressions surveyed in Barro 1997 or Durlauf \& Quah 1999) are perhaps less mainstream within conservation science, although a large number of economic studies of tropical deforestation employing relatively sophisticated methods have existed since the late 1980s (see, for example, the review in Kaimowitz \& Angelsen 1998). While an understanding of how politics - like corruption - affect resource outcomes is surely required for better polieymaking, simple statistical models may at best be misleading, and at worst counterproductive.

\section{Corruption and Natural Resources: The Complex Conceptual Links}

There is growing interest in the effect of government quality on economic, political and environmental outcomes. It is widely accepted that governments that are less corrupt and that have more efficient bureaucracies - i.e., have better "governance" - produce more effective policy (Tendler 1997). Indeed, several policies emanating from donors, watchdog non-governmental organizations, and trade groups seek to incorporate explicitly measures to foment the better governance of forest resources, for example Transparency International's Forest Integrity Network, the International Tropical Timber Organization's policy forum on criminal activity in the forest sector, the U.S. Government's Congo Basin Initiative, and the Center for International Forestry Research's newly-created forest governance division. The World Bank also emphasizes the role of good governance within its forest sector strategy as well as more broadly in its poverty reduction programs (World Bank 1997, 2002). And the United States' Millennium Challenge Corporation seeks to link the process of good governance with 
environmental measures in deciding how to allocate its portfolio of foreign aid. The objective of checking the abuse of power by officials is laudable.

But corruption cuts across the private and public sectors, takes multiple forms, exists at multiple scales, may have both direct and indirect effects on natural resources, and is almost surely endogenous to the broader socioeconomic systems it infects. These basic features complicate analysis enormously. The existing empirical literature ignores most of this complexity, employing an oversimplified model that yields unreliable results because it rests fundamentally on unstated and untested assumptions. While it lies beyond the scope of this paper to develop a full-blown theory of the relationship between corruption and the state of natural resources, in the following few paragraphs we sketch out a few of the basic structural issues to illustrate the inherent ambiguity in this relationship and the danger of reading too much into the results of oversimplified statistical models. In the next section we demonstrate how easy it is to reverse those results with modest, reasonable changes to the specification of an oversimplified model.

Let us first establish an appropriate benchmark from the existing literature (e.g., McPherson and Nieswiadomy 2000, R. Smith et al. 2003, Katzner 2005), which we label the conventional model of the links between corruption and natural resources. It assumes that developing countries suffer from entrenched patronage politics, lack the rule of law, have low paid civil servants, and "non-existent accountability" (Smith and Walpole 2005). When natural resources become valuable in such a context, officials from top to bottom will be coerced, bribed, or lured into overexploiting the valuable species 
(Laurence 2004). No one within the political system is held responsible for such behavior. Even the injection of foreign aid targeted for conservation is susceptible to these same forces. The result is that resources decline, sometimes precipitously.

Studies employing the conventional model have thus far focused on national level political corruption - defined as public office holders' abuse of their power for private gain (Bardhan 1997, World Bank 1997, Transparency International 2004) - and understandably so. Data availability sharply limits analysts' ability to study these phenomena at smaller scales. Yet in a recent summary of lessons learned in natural resource conservation activities in Africa, the United States Agency for International Development (2002) emphasizes the importance of good governance at the local level and the considerable variation apparent in local level resource governance. Moreover, the characteristic of the resources in question - e.g., migratory or stationary, valuable in small or large forms, easy or difficult to access and to monitor - varies enormously within countries Such characteristics are fundamental determinants of the appropriate structure of resource governance and how deleterious the potential consequences of bad governance, including corruption, might be (Ostrom 1990). Given all the possible subnational variation in resource characteristics and quality of governance, a single measure of corruption at the national level seems highly unlikely to capture whatever true relationship(s) might exist between corruption and resource outcomes.

Even within the realm of national-level political corruption, however, the relationship need not be as neat as the conventional model would have it. Start with the problem of 
administrative corruption, which can be crudely separated into collusive and noncollusive forms, the former occurring where public officials conspire with violators of resource use regulations to facilitate illegal exploitation, the latter occurring where public officials extract rents before approving legal uses, as when a ministry functionary demands a bribe before issuing a proper logging permit (J. Smith et al. 2003, Laurance 2004). The direct effect of non-collusive corruption is to increase the cost of resource use, which will tend to slow rather than accelerate degradation. The unstated assumption in the conventional model is that administrative corruption is collusive, although this is certainly not uniformly true. Indeed, we know little about the relation between collusive and non-collusive corruption — are they complements or substitutes? — and the national level corruption measures used make no distinction between the two forms, making inference problematic (for a review on the concept of political corruption, see Kitschelt 2000).

The second key distinction is between administrative corruption of the sort just discussed, which concerns compliance with laws and policies taken as given, and political corruption associated with the setting of laws and policies by senior officials (Rose Ackerman 1978). At the level of political corruption there again emerge at least two countervailing pressures, rendering ambiguous the relation between corruption and resource state. First, in so far as resource extraction is financially valuable, individuals and firms may find it attractive to make (potentially legal) financial contributions so as to induce permissive policies with respect to fees, access, emissions, etc. The result may be increased resource degradation through legal overexploitation (OECD 2003). 
Agricultural, energy and fisheries policies in many wealthier countries with high governance scores offer good examples.

On the other hand, political corruption historically tends to favor urban populations and manufacturing in developing countries (Lipton 1977, Bates 1981). This commonly leads to overvaluation of the local currency and rural-to-urban migration, reducing the global competitiveness of primary products, diminishing population pressure in many fragile rural areas, and potentially discouraging natural resource exploitation (Wunder 2003).

Furthermore, the links between administrative and political corruption remain very unclear. For example, it may be that where increased competition reduces political corruption and policies that facilitate degradation, administrative corruption may grow as the gains increase to avoiding more restrictive resource use policies (Wilson and Damania 2005). Thus, improvements in one domain need not be accompanied by progress in the other.

Beyond the various, countervailing direct effects of administrative and political corruption, the indirect effects are likewise unclear. The evidence that corruption retards economic growth is considerable (Kaufman 1997). But as a vast literature on the socalled "environmental Kuznets curve" reveals, the effect of slower economic growth on the environment may be positive over some ranges and negative over others (Lee and Barrett 2000, Brock and Taylor 2005). By retarding investment, corruption may slow expansion of the agricultural frontier, pollution of waterways, and direct exploitation of 
fisheries, forests, and wildlife. On the other hand, slower growth among poor populations can stimulate resource degradation in the absence of emerging livelihoods that do not depend upon primary product extraction.

The foregoing, informal mapping of the various pathways through which corruption - of different sorts and at different levels - might affect the state of natural resources, even controlling for prospective confounding variables, underscores that our theoretical understanding about the relationship between corruption and biodiversity remains very underdeveloped. Empirical tests are challenged not only by underdeveloped theory but also by the difficulties of gathering data at appropriate spatial scale and of integrating necessary biophysical and socio-politico-economic data, not least of which with respect to different types of corruption.

But perhaps the biggest problem is the inherent endogeneity of corruption. The state of governance co-evolves with the economy and the natural resources base. In observational data it is commonly difficult to disentangle true and spurious correlation the latter due to common correlation with an omitted relevant variable - much less to move beyond establishing correlation to infer causality. For example, civil wars may lead to corruption in government but are also highly likely to affect the ability of that government to protect natural resources. A volatile political system (for example, transitions from autocracy to democracy in Africa) and even volatile climate (reducing animal populations, increasing the value of corruption to politicians in the face of bad harvests) may act in the same manner. Low rates of economic growth could increase 
corruption as stressed bureaucrats seek supplements to their meager government salaries while encouraging government to redouble efforts to protect natural resources that might enhance its tourism revenue, as was the case in Kenya through much of the Moi era.

\section{Testing for links between corruption and biodiversity}

The conceptual underpinnings of the conventional model are thus oversimplified, assuming away many of the countervailing effects at different spatial and temporal scales of analysis, and neglecting a host of possible confounding variables. Lacking a well defined theory, one should exercise great caution when interpreting empirical results (Ferraro 2005, Katzner 2005, Walpole and Smith 2005). Statistical findings based on the conventional model are at once tests of the relation under investigation and of the assumptions underlying the statistical model. At the very least, we must see if statistical findings hold under simple robustness checks.

In this section we demonstrate how relatively modest adjustments to the statistical specifications used in studies based on the conventional model, even using the same data, can generate completely contrary results. Statistical findings under the conventional model are simply not robust to reasonable, but inherently arbitrary, changes to the set of explanatory variables or to estimation methods. We emphasize that the specific statistical results we present momentarily should not be taken particularly serioușly in informing the important debate about the effect of corruption on biodiversity. Our results could quite easily change completely if one were to include additional variables on as-yet unmeasured features of the societies and ecosystems in questions or if data could be 
better matched across spatio-temporal scales of analysis. Our objective is not to offer conclusive results, but merely to demonstrate that findings under the conventional model, ours included, should not be taken very seriously.

Towards this end, we use the widely-cited R.Smith et al. (2003) Nature study as a foil. R. Smith et al. use national level indicators of corruption and biodiversity in a cross national design; and find that there are significant and negative relationships between corruption and changes in elephant and rhinoceros populations, and in forest cover. Although the authors were careful in the prose describing their statistical results to speak in terms of correlations and associations, rather than causal links, the supporting text and interpretations by many readers we have spoken with worldwide - suggests that corruption causes biodiversity loss. In this section we explore how the Smith et al. study generated its findings and demonstrate how they are not robust to simple, appropriate refinements. We want to underscore that the critiques we offer apply equally to other applications of the conventional model, including those that generate results contrary to Smith et al.'s, such as Katzner (2005). ${ }^{l}$

\section{Forests}

Empirical research using cross-country data to explore the government-related causes of deforestation in particular has grown rapidly since the early 1990s. Earlier case study research found that weak property rights were associated with loss of forest cover (Gillis 1980; Repetto \& Gillis 1988; Vincent 1990; Southgate et al. 1991; Alston et al. 1996; 
Godoy et al. 1996; Pinchon 1997). Using panel data, cross national studies substantiated this claim (Deacon 1994, 1999; Bohn \& Deacon 2000). These studies did not measure corruption per se, but rather factors directly affected by governments that might affect forests.

In their investigation of forests, R. Smith et al. use two different dependent variables, change in total forest cover and change in natural forest cover from 1990 to 1995 , to estimate the correlations between forests and governance. The authors examine the effect of governance scores (on which, more below), per capita gross domestic product (GDP), Human Development Index (HDI) score, and population density on change in forest cover. They find that change in total forest cover correlates positively with per capita GDP and governance, but change in natural forest cover does not correlate with governance. The authors therefore suggest that the "result for total cover was driven by the establishment of new plantations in wealthier, better-governed countries" (p.68).

These conclusions are not robust because Smith et al. comparison of natural and total forest cover uses different samples. The United Nations Food and Agriculture Organization (FAO) reports forest cover for all countries, but reports natural forest cover only for developing nations. Thus a correct test of the difference between determinants of natural forest cover versus total forest cover must restrict the total forest cover to developing countries only in order to rule out that the results are purely an artifact of different country samples for each measure of forest cover. When we restrict total forest

\footnotetext{
${ }^{1}$ We do not examine Smith et al.'s statistical model of rhinoceros populations and corruption since they have only nine observations. Tests with such a small sample size are unlikely to produce much useful
} 
cover to developing countries we find that neither per capita GDP nor governance have any statistically significant relation to changes in total forest cover, while HDI is now negatively related to forest cover and barely statistically significant at the $10 \%$ level(Table I). ${ }^{2}$ Consequently, it appears that Smith et al.'s results are simply a function of sample selection bias.

We can demonstrate the effect of sample selection bias graphically (Figure 1). The graph reveals two clusters of countries, (1) a relatively large group with low governance scores and negative changes in forest cover (marked with Xs) and (2) a relatively small group with high governance scores and positive forest cover change (marked with circles). The Xs represent developing countries; the circles represent developed countries. The graph also shows two best fit lines. The thick line is the best fit for developing countries; the thin line is the best fit for all countries. The slope of line for developing countries is statistically indistinguishable from the zero-slope line at conventional significance levels. Thus, the only defensible inference to draw is that forest cover tended to increase in developed countries between 1990 and 1995. There are few policy implications from such a result.

information and are inherently very fragile, so there is no need to underline that fragility further.

${ }^{2}$ Data for change in forest cover, corruption, per capita GDP, Human Development Index (HDI), and population density are precisely those used by Smith et al. (available online at http://www.naturexom/nature/journal/v426/n6962/extref/nature02025-sl.pdf). Because we have one observation per country, we estimate the model using ordinary least squares and correct for heteroskedasticity. Estimation details available from authors by request. 
Third, the authors correlate the change in forest cover with mean governance score over a single period. The implications one can draw from such tests are unclear. An average cannot identify whether conditions are improving, deteriorating, or unchanged, so one cannot infer that improvements in governance would lead to increased forest cover. The problem here is that variation in cross-section carries no implications for (unobserved) variation in time series. One would prefer to study how the stock of a natural resource changes in response to changes in governance. If we revisit R.Smith et al.'s data, using changes in forest cover and in governance, rather than levels, the correlation between the change in governance and change in forest cover is -0.21 , neither positive nor statistically significant. Simple correlations of levels cannot adequately capture the relationship between biological, economic, and political factors.

\section{Elephants}

R.Smith et al. use similar techniques to analyze the relation between corruption and populations of African elephants and black rhinoceroses. As in their study of forests, they test the effects of governance, per capita GDP, mean HDI, and mean population density, as well as a measure of spending per $\mathrm{km}^{2}$ of protected area within countries, on changes in African elephant populations. In these tests the authors use step wise regression, and find that only mean governance scores for the period 1987 - 1994 explain the change in these populations. The authors conclude that "These results suggest that political corruption may play a considerable role in determining the success of national strategies to conserve these two flagship species, despite the international attention they both attract" (p.68). 
But once again, these results are not robust. By adding more data from the same series to their study, and including omitted variables that are prospectively relevant, R. Smith et al.'s results change completely.

Data exist for African elephants over three periods from the same data series, the African Elephant Database 1987 (Burrill \& Douglas-Hamilton 1987), 1994 (Said et al. 1995), 1997 (Barnes et al. 1999), and 2002 (Blanc et al. 2003), although R.Smith et al. only use the first two. ${ }^{3}$ It turns out that the correlation between change in elephant population and national level corruption is highly sensitive to specific time periods: the correlation is 0.40 between 1987 and 1997, but changes to -0.32 between 1997 an 2002 .

Moreover, the regression results are not robust to inclusion of additional plausible control variables. Simply including a country's latitude changes the results fundamentally. Latitude in fact better explains change in elephant populations than does the national corruption measure. Using the R.Smith et al.'s data, a regression of the change in elephant population on governance and latitude yields the following equation (p-values in parentheses): change in elephant $=-73.8(<.01)+10.1 *$ Governance $(0.14)+-$ $2.4 *$ Latitude $(<01) ;$ R-squared $=0.78 ; \mathrm{N}=20$.

\footnotetext{
${ }^{3}$ The numbers R.Smith et al. use for the 1987 elephant numbers do not correspond to the publicly available African Elephant Database. By email communication, Dr. Smith explained that he received new data from the IUCN that he helpfully provided us so as to ensure any differences in statistical findings are not due to differences in the data: Ghana (3,900), Kenya (35,000), Tanzania (100,000), and Uganda (3,000).
} 
Moreover, a step toward a properly specified model of a species' population dynamics would include other factors that account for elephant population change, such as covariates reflecting basic anthropogenic and biophysical factors likely affect to elephant fertility and mortality. In a modest step in that direction, we regressed the annual growth rate in national elephant population ${ }^{4}$ on the natural logarithm of the lagged elephant population - the coefficient on which then reflects the effect of a one percent change in base period population on the rate of growth, also measured in percentage terms - and rainfall, as two basic biophysical variables likely to affect population growth rates through recruitment rates. Because we would expect forest and savannah elephants to respond differently at the same levels of rainfall, given the stark difference in their habitats, we use deviations from country-specific mean average annual rainfall levels, 1987-2002, as our explanatory variable..$^{5}$

We also add two anthropogenic covariates to which we alluded earlier: the presence of civil war, and tourists per hectare of protected area. The former is just a dummy variable taking value one if there was an intrastate conflict with more than a 1000 human deaths, zero otherwise (Gleditsch \& Ward 2004). Tourist data come from the World Bank (2004). Since no data exist on the actual spatial dispersion of tourists or on conservation enforcement levels over the sample time frame, tourists per protected area offers a very rough proxy, since the presence of tourists can increase elephants through both the

\footnotetext{
${ }^{4}$ We estimate the annual average (compound) growth rate in elephant population between survey periods using the formula $\mathrm{POP}_{\mathrm{s}+\mathrm{t}}=\left(1+\mathrm{r}^{\wedge} \mathrm{POPs}\right.$ where $\mathrm{t}$ is years between counts, $\mathrm{r}$ is the annual growth rate, and $\mathrm{s}$ is the initial period.

${ }^{5}$ Source: Global Historical Climatological Network (2004).
} 
informal enforcement effect of tourists, increased government agents in the field due to tourists, and the incremental revenue tourists provide for conservation activities.

Finally, we include a measure of corruption. Standard measures of corruption, like the ones used by R.Smith et al., provide a single, national level of corruption for a country annually. They use the Corruption Perceptions Index (CPI) measure (CPI website: http://www.transparency.org/surveys/index.html). But CPI data does not cover the years for which they have data on their dependent variables, so they construct their measure of corruption using another well- measure of corruption, International Country Risk Guide. These two measures of corruption are highly correlated and widely known. We use the latter as it covers the entire period under investigation and is thus more precise.

Our hypotheses about these factors and their associated measures are in Table 2. Data for elephant populations are from all periods covered by the African Elephant Database. We must add the caution, however, that the editors of the elephant database specifically warn against such empirical studies because contributors to these reports make clear that different counting methods over space and time were used, making comparisons between counts tenuous. ${ }^{6}$

\footnotetext{
${ }^{6}$ The sampling error of the most widely used counting protocols - e.g., dung count and aerial surveys - are also different, and they are also used in different ratios from year to year in different countries. In some cases, more accurate protocols for counting would lead to a decline in the number of elephants reported, regardless of other factors (R. Barnes, editor of 1995, 1998, 2002 African Elephant Databases, personal communication, December 2003).
} 
With these various caveats in mind, we regress the growth rate of national-level elephant population on its lagged level and our explanatory variables using a random effects panel data estimator with a standard error correction to account for likely heteroskedasticity (Table 3). The results suggest that the two anthropogenic factors - civil war and tourists per protected area - are significant predictors of African elephant population change. Civil wars are associated with reduced elephant populations, most likely through mortality (more humans with guns in these zones seek meat and cash) and elephant outmigration. Growth in tourism is positively associated with elephant populations, although the direction of causality in this relation is unclear.

As one would expect, biophysical factors also matter to elephant population stocks. Population dynamics appear to be convex over the sample range in that estimated growth rates are positively and significantly related to the lagged stock level. Stocks are also increasing in deviation from national average rainfall, which others have attributed to rainfall's effect on elephant fecundity, infant mortality, and local labor supply for poaching (Barrett \& Arcese 1998).

The point is not to argue that we have an airtight explanation of change in elephant populations. These results are subject to many of the criticisms we made earlier. Rather, the punch line is that once we control for a few plausible anthropogenic and biophysical conditioning factors, estimate the effects in changes rather than levels so as not to confound cross-sectional and longitudinal variation, and incorporate additional observations from the same data sources, corruption levels no longer have any 
explanatory power. This once again underscores the fragility of apparent statistical relationships between measures of central government corruption and conservation outcomes such as forest cover or the population of a protected species under the maintained hypotheses of the conventional model. Although anecdotal and simple statistical evidence leads observers to hypothesize about connections between corruption and conservation, without careful and explicit modeling of the pathways through which such effects might occur, empirical exercises such as those popularized in recent years are likely to generate fragile, even misleading results.

\section{Conclusion}

There is growing interest in explaining conservation outcomes through political processes. This is certainly an appropriate direction in which to push research; no resource is immune from the direct or indirect forces resulting from government policy or the political process (Ascher 1999). But studies of the links between corruption and outcomes on the landscape will need more careful modeling and testing than has been the norm to date. This paper discussed the many ways that corruption may be linked to overexploitation, each representing a different causal path from human action to environmental outcome, some implying a negative relation, others a positive one. Using one especially well-known recent study as a foil, we then demonstrated the fragility of statistical studies based on the oversimplified, conventional model relating governance to resource state. The links between national governments and natural resources are many

\footnotetext{
${ }^{7}$ Using population levels rather than the change in elephant population as the dependent variable yields similar findings. Detailed results available from the authors by request.
} 
and tangled. Additional work attempting to bridge the social and natural sciences is clearly needed to better explain these important and complex relationships. 


\section{Literature Cited}

Adsera, A, C. Boix, and M. Payne. 2003. Are you being served? Political accountability and quality of government. Journal of Law, Economics, and Orgänization. 19(2): 445-490.

Alston, L.J., G.D. Libecap, and R. Schneider. 1996. The determinants and impact of property rights: land titles on the Brazilian frontier. Working Paper 5405. National Bureau of Economic Research, Cambridge, Massachusetts.

Ascher, W. 1999. Why governments waste natural resources: policy failures in developing countries. Johns Hopkins Press, Baltimore, Maryland.

Bardhan, P. 1997. Corruption and development: a review of the issues. Journal of Economic Literature 35: 1320-1346.

Barnes, R., C. Craig, H. Dublin, G. Overton, W. Simons, and C. Thouless. 1999. African elephant database 1998. International Union for Conservation of Nature, Gland, Switzerland.

Barrett, C, and P. Arcese. 1998. Wildlife harvest in integrated conservation and development projects: linking harvest to household demand, agricultural production and environmental shocks in the Serengeti. Land Economics 74: 449-65.

Barrett, C.B., K. Brandon, C. Gibson, and H. Gjertsen. June 2001. Conserving tropical biodiversity amid weak institutions. BioScience 51(6): 497-502.

Barro, R.J. 1997. Determinants of economic growth. MIT Press, Cambridge, Massachusetts.

Blanc, J., C. Thouless, J. Hart, H. Dublin, I. Douglas-Hamilton, C. Craig, and R. Barnes. 2003. African elephant status report 2002. International Union for Conservation of Nature, Gland, Switzerland.

Bohn, H., and R.T. Deacon. 2000. Ownership risk, investment, and the use of natural resources. American Economic Review 90: 3, 526-549.

Brock, W. and Taylor, M. S. 2005. Economic growth and the environment: a review of theory and empirics. In The Handbook of Economic Growth, ed. S. Durlauf and P. Aghion. Amsterdam, North Holland.

Burrill, A. and Douglas-Hamilton, I. 1987. African elephant database. United Nations Environment Programme, Nairobi, Kenya.

Callister, D.J. 1992. Illegal tropical timber trade. TRAFFIC International, Cambridge, United Kingdom.

Contreras-Hermosilla, A. 1997. Country sector planning. Proceedings of the XI World Forestry Congress 5: 279-284. Antalya, Turkey.

Crook, R. C. 2003. Decentralisation and poverty reduction in Africa: The politics of local-central relations. Public Administration and Development 23(1): 77-88.

De Bohan, V., N. Doggart, J. Ryle, S. Trent, and J. Williams. 1996. Corporate power, corruption and the destruction of the world's forests. Environmental Investigation Agency, London.

Deacon, R. T. 1994. Deforestation and the rule of law in a cross-section of countries. Land Economics 70(4): 414-430.

Deacon, R. T. 1999. Deforestation and ownership. Land Economics 75(3):341-359. 
Durlauf, S. and D. Quah. 1999. The new empirics of economic growth. In J. Taylor and M. Woodford editors. Handbook of macroeconomics. Volume 1A. North Holland, Amsterdam.

Ferraro, P. 2005. Corruption and conservation: the need for empirical analyses: a response to Smith \& Walpole. Forthcoming, Oryx 39.

Garman, C, S. Haggard, and E. Willis. 2001. Fiscal decentralization: a political theory with Latin American cases. World Politics 53(2): 205-36.

Gibson, C. 1999. Politicians and poachers: the political economy of wildlife policy in Africa Cambridge University Press, Cambridge.

Gibson, C, Ostrom, E., and J. Williams. 2005. Local enforcement and better forests. World Development 33(2): 273-284.

Gillis, M. 1980. Fiscal and financial issues in tropical hardwood concessions. Development discussion paper No. 110. Harvard Institute for International Development, Cambridge, Massachusetts.

Gleditsch, K. and M. Ward. 2004. War and peace in time and space: the role of democratization. International Studies Quarterly 44(1): 1-29. The data on civil war can be found at http://weber.ucsd.edu/ kgledits/expwar.html.

Global Historical Climatology Network. 2004. http://iridl.ldeo.columbia.edU/SOURCES/.NOAA/.NCDC/.GHCN/.v2beta/.

Godoy, R., J.R. Franks, D. Wilkie, M. Alvarado, G. Gray-Molina, R. Roca, J. Escobar, and M. Cárdenas. 1996. The effects of economic development on neotropical deforestation: household and village evidence from Amerindians in Bolivia. Development discussion paper No. 540. Harvard Institute for International Development, Cambridge, Massachusetts.

Grove, Richard. 1993. Conserving Eden: The East India Companies and their environmental policies on St. Helena, Mauritius, and in western India, 1660-1854. Comparative Studies in Society and History 35:318-51.

Guha, Ramchandra [1989] 2000. The unquiet woods: ecological change and peasant resistance in the Himalaya. Oxford University Press, New Delhi.

Hecht, S. and A. Cockburn. 1989. The fate of the forest. Verso, New York.

Kaimowitz, D. and A. Angelsen. 1998. Economic models of tropical deforestation: A review. CIFOR, Bogor, Indonesia.

Katzner, T.E. 2005. Corruption - a double-edged sword for conservation? A response to Smith \& Walpole. Forthcoming, Oryx 39.

Kaufman, D. 1997. Corruption: the facts. Foreign Policy 107: 114-131.

Kitschelt, H. 2000. Linkages between citizens and politicians in democratic politics. Comparative Political Studies 33 (6/7): 845-879.

Krishnaswamy, A. and A. Hanson. 1999. Summary report: World Commission on Forests and Sustainable Development. World Commission on Forests and Sustainable Development, Winnepeg.

Lee, D.R. and C.B. Barrett. 2000. Tradeoffs or Synergies? Agricultural Intensification, Economic Development and the Environment in Developing Countries. CAB International, Wallingford, United Kingdom.

McPherson, M.A. and M.L. Nieswiadomy. 2000. African elephants: the effect of property rights and political stability. Contemporary Economic Policy 18: 14-26.

Myers, N. 1979. The sinking ark. Pergamon, New York. 
Organisation for Economic Co-operation and Development (OECD). 2003. Environmentally harmful subsidies in OECD countries. OECD, Paris.

Peluso, Nancy L., and Peter Vandergeest. Genealogies of the political forest and customary rights in Indonesia. Journal of Asian Studies 60(3): 761-812.

Pichón, F. J. 1997. Colonist land-allocation decisions, land use, and deforestation in the Ecuadorian Amazon frontier. Economic Development and Cultural Change 44(4): 127-164.

Repetto, R., and M. Gillis, eds. 1988. Public policies and the misuse of forest resources. Cambridge University Press, Cambridge.

Rose Ackerman, S. 1978. Corruption: a study in political economy. Academic Press, New York.

Ross, M. 1996. Timber booms and institutional breakdown in Southeast Asia: Cambridge University Press, Cambridge.

Said, M, R. Chunge, C. Craig, C. Thouless, R. Barnes, and T. Douglass. 1995. African elephant database 1995. International Union for Conservation of Nature, Gland, Switzerland.

Scott, James C. 1972. Patron-client politics and political change in Southeast Asia. American Political Science Review 66(1): 91-113

Smith, J., K. Obidzinski, K. Subarudi and I. Suramenggala. 2003. Illegal logging, collusive corruption and fragmented governments in Kalimantan, Indonesia. International Forestry Review 5: 293-302.

Smith, R.J., R.D.J. Muir, M.J. Walpole, A. Balmford, andN. Leader-Williams. 6 Nov 2003. Governance and the loss of biodiversity. Nature 426: 67-70.

Southgate, D., R. Sierra, and L. Brown. 1996. The causes of tropical deforestation in Ecuador. World Development 24(7): 1151-60.

Stokes, Susan C. 1997. Democratic accountability and policy change: economic policy in Fujimori's Peru. Comparative Politics 29(2): 209-260.

Tendler, J. 1997. Good governance in the tropics. Johns Hopkins University Press, Baltimore, Maryland.

Transparency International. 2004. Global Corruption Report 2004. Transparency International, Berlin.

United States Agency for International Development (USAID). August 2002. Nature, wealth and power: emerging best practice for revitalizing rural Africa. Environment and Natural Resources Team, Sustainable Development Office, Africa Bureau, USAID, Washington, D.C.

Vincent, J.R. 1990. Rent capture and the feasibility of tropical forest management. Land Economics 66(2): 212-223.

Walpole, M.J. and R.J. Smith. 2005. Focusing on corruption: a reply to Ferraro and Katzner. Forthcoming, Oryx 39.

Wilson, J.K. and R. Damania. 2005. Corruption, political competition and environmental policy. Journal of Environmental Economics and Management 49: 516-535.

World Bank. 1997. Helping countries combat corruption: the role of the World Bank. World Bank, Washington, D.C.

World Bank. 2002. A revised forest strategy for the World Bank. World Bank, Washington, D.C.

World Bank. 2004. World Development Indicators 2004. World Bank, Washington, D.C. 
Wunder, S. 2003. Oil wealth and the fate of the forest: a comparative study of eight tropical countries. Routledge, London. 
Table 1: Forest cover for all countries and developing countries

\begin{tabular}{|c|c|c|c|c|c|c|}
\hline \multirow[b]{2}{*}{ Population density } & \multicolumn{3}{|c|}{$\begin{array}{l}\text { Forest Cover } \\
\text { (All countries) } \\
\text { [Smith et al.] }\end{array}$} & \multicolumn{3}{|c|}{$\begin{array}{l}\text { Forest cover } \\
\text { (Developing countries only) }\end{array}$} \\
\hline & $\begin{array}{l}-0.000 \\
(0.52)\end{array}$ & $\begin{array}{l}-0.000 \\
(0.19)\end{array}$ & $\begin{array}{l}-0.000 \\
(0.89)\end{array}$ & $\begin{array}{l}-0.000 \\
(0.42)\end{array}$ & $\begin{array}{l}-0.000 \\
(0.49)\end{array}$ & $\begin{array}{l}-0.000 \\
(0.52)\end{array}$ \\
\hline governance & $\begin{array}{l}0.232 \\
(7.03)^{c}\end{array}$ & & & $\begin{array}{l}0.135 \\
(1.03)\end{array}$ & & \\
\hline HDI & & $\begin{array}{l}1.956 \\
(4.08)^{c}\end{array}$ & & & $\begin{array}{l}-1.263 \\
(1.77)^{a}\end{array}$ & \\
\hline Per capita GDP & & & $\begin{array}{l}0.000 \\
(6.54)^{c}\end{array}$ & & & $\begin{array}{l}0.000 \\
(1.47)\end{array}$ \\
\hline Constant & $\begin{array}{l}-1.702 \\
(9.46)^{c}\end{array}$ & $\begin{array}{l}-1.930 \\
(6.09)^{c}\end{array}$ & $\begin{array}{l}-0.954 \\
(8.03)^{c}\end{array}$ & $\begin{array}{l}-1.507 \\
(3.36)^{c}\end{array}$ & $\begin{array}{l}-0.307 \\
(0.82)\end{array}$ & $\begin{array}{l}-1.166 \\
(8.31)^{C}\end{array}$ \\
\hline Observations & 94 & 88 & 93 & 66 & 60 & 65 \\
\hline R-squared & 0.28 & 0.12 & 0.22 & 0.02 & 0.05 & 0.02 \\
\hline
\end{tabular}

Robust $t$ statistics in parentheses

${ }^{a}$ significant at $10 \% ;{ }^{b}$ significant at $5 \% ;{ }^{c}$ significant at $1 \%$ 
Table 2: Hypotheses, variables, and measures for elephant analysis

Hypotheses

Previous level of elephants to control for potential nonlinear elephant population dynamics.

Rainfall affects fecundity/infant mortality as well as local labor supply for poaching

Civil war increases elephant poaching

Increased conservation enforcement decreases elephant poaching Corruption decreases elephants due to increased, unsustainable (potentially illegal) offtake.
Measures

Lagged elephant population level, from African Elephant Database (various years).

Change in three year average of rainfall before elephant count (elephants have 24 month gestation). Source: Global Historical Climatology Network (2004) Occurrence of civil war in country at time of count. Source: Gleditsch (2004)

Change in number of tourists per hectare of protected area. Source: World Bank (2004). Change in ICRG measure of contuption 
Table 3: Random effects panel data regression model for growth rate of elephants

\begin{tabular}{ll}
\hline Log of lag level of elephants & 0.02 \\
& $(2.26)^{b}$ \\
Civil war & -0.10 \\
& $(3.95)^{c}$ \\
Change in tourists per hectare of & 0.03 \\
protected area & $(2.22)^{b}$ \\
& 0.08 \\
Change in rainfall & $(1.74)^{a}$ \\
& 0.03 \\
Change in corruption & $(1.19)$ \\
& -0.18 \\
Constant & $(2.39)^{b}$ \\
\hline Observations & 45 \\
R-Squared (overall) & 0.37 \\
\hline Absolute value of $\mathrm{z}$ statistics (based on robust standard errors) in \\
parentheses & \\
${ }^{a}$ significant at $10 \%{ }^{b}{ }^{b}$ significant at $5 \%{ }^{c}{ }^{c}$ significant at $1 \%$
\end{tabular}




\section{Figure Legends}

The cluster of Xs represents developing countries and the cluster of circles represents developed countries. The thick line with the relatively flat slope is the best fit line for developing countries; the thin line with the positive slope is the best fit for all countries. 
Figure 1.

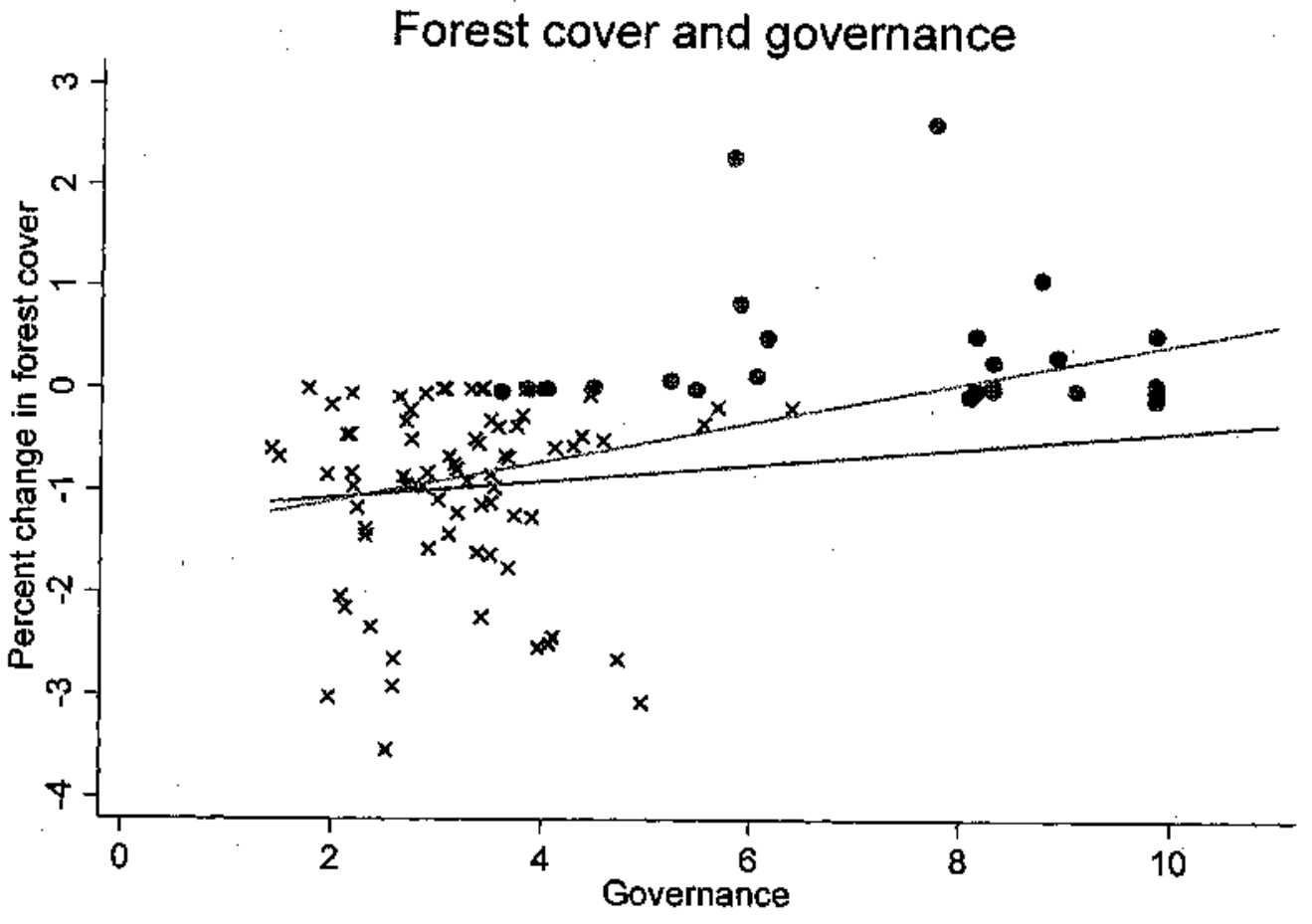

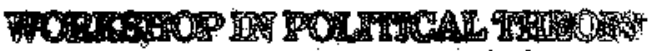
AND POLICI ANALTED

5135 HORTII PADT

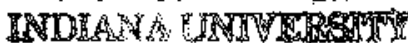

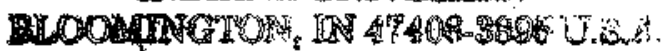

